\title{
A New Method to Measure the Performance of Leveraged Exchange-Traded Funds
}

\author{
Narat Charupat \\ DeGroote School of Business \\ McMaster University \\ 1280 Main Street West \\ Hamilton, Ontario L8S 4M4, Canada \\ Tel: (905) 525-9140 Ext. 23987 \\ Fax: (905) 521-8995 \\ E-mail: charupat@mcmaster.ca \\ and \\ Peter Miu \\ DeGroote School of Business \\ McMaster University \\ 1280 Main Street West \\ Hamilton, Ontario L8S 4M4, Canada \\ Tel: (905) 525-9140 Ext. 23981 \\ Fax: (905) 521-8995 \\ E-mail: miupete@mcmaster.ca
}

This version: June 2014

\begin{abstract}
We examine the effects of daily return compounding, financing costs, and management factors on the performance of leveraged exchange-traded funds (LETFs) over various holding periods. We propose a new method to measure LETFs' tracking errors that allows us to disentangle these effects. Our results show that the compounding effect generally has more influence on tracking errors than other factors, especially for long holding periods and in a "sideways" market. The explicit costs (i.e., the expense ratios) and other factors (e.g., financing costs) can materially affect the performance of LETFs, especially for those with high leverage ratios and bear funds.

JEL classification: G10; G12; G23

Keywords: Exchange-traded funds; Leverage; Tracking errors; Regression analysis; Bull funds; Bear funds

\footnotetext{
${ }^{*}$ Corresponding author. We would like to thank the anonymous referee and the editor for their helpful suggestions. We also thank Donghui Chen and Yue Zhang for research assistance. The financial support from the Social Science and Humanities Research Council is gratefully acknowledged.
} 


\section{Introduction}

A leveraged exchange-traded fund (LETF) is a publicly-traded fund that promises to provide daily returns that are in a multiple (positive or negative) of the returns on an index. To meet that promise, the fund uses leverage, which is typically obtained through derivatives such as futures contracts, forward contracts, and total-return swaps. The amount of leverage is adjusted daily so that the proportional leverage (and thus the multiple) remains constant from day to day.

In the US market, the first LETF was introduced in 2006. By the end of 2012, there were over 200 LETFs with total assets of approximately \$30 billion. Their underlying indices include stock indices, bonds, currencies, commodities, and real estate. The available multiples are double leverage $(+2 x$ and $-2 x)$ and triple leverage $(+3 x$ and $-3 x)$. There are also inverse ETFs, which provide daily returns equal to the negative of the underlying index returns (i.e., multiple $=$ $-1)$.

LETFs are not for long-term, buy-and-hold investors, because the constant maintaining of leverage ratios will cause LETFs' long-term compounded return to deviate from the multiple of the underlying index return over the same period. The magnitude and the direction of the deviation depend on the length of the holding period and the path that the underlying benchmark takes during that period. For a given holding period, the higher the multiple (in absolute terms) or the more volatile the underlying index returns (or both), the greater the chance that a LETF's realized return will differ from its stated multiple.

The performance of exchange-traded funds is measured by tracking error, commonly defined as the deviation of the returns on net asset values (NAVs) from the returns on the underlying indices. Conventionally, a fund's tracking errors may be estimated by: (1) calculating 
the standard deviation of the difference between the fund's NAV returns and the returns on its underlying index; and (2) regressing the fund's NAV returns on the underlying index's returns. These approaches are commonly used in studies on traditional (i.e., +1x) ETFs and index mutual funds (e.g., Frino and Gallagher, 2001; Elton, Gruber, Comer, and Li, 2002; and Gastineau, 2004). However, these conventional approaches can lead to ambiguous results when used with LETFs and inverse ETFs (hereafter, collectively referred to as "LETFs"). This is because the tracking errors of these funds are dictated not only by factors that are under the control of the fund issuers (e.g., fees, expenses, replication techniques, transaction costs, and the accrual of cash), but also by factors that are outside of their control (e.g., the compounding effect and financing costs).

It is important to understand how the compounding effect, financing costs, and the management factors influence LETFs' tracking errors. In this study, we analyze these effects and propose a new method to measure tracking errors that explicitly controls for the compounding effect. We then apply this method to a sample of inverse, double- and triple-leveraged funds. We show that, depending on the return paths of the underlying indices, the effect of compounding can constitute a very large portion of the total tracking errors. By screening out the compounding effect, our proposed method is more precise and appropriate than the conventional measures for examining the performance of LETFs. We also consider an extension of our proposed method that allows us to simultaneously control for any difference in the financing costs involved in delivering the target leverage returns. By enabling us to isolate the portion of the tracking errors that can be fully attributed to management factors, our proposed methodology provides us with the necessary metrics to compare the management efficiency of different LETFs. 


\section{LETFs' tracking ability}

The ability of an LETF to track its underlying index depends on a number of factors. The first group of factors is directly related to how the fund is managed, and is generally under the control of the fund's management. These factors include investment advisory and management service fees, transaction costs, management of dividend distribution, and the choice of replication strategy. We refer to these factors as management effects. We expect that funds that are more efficiently managed will have smaller tracking errors as a result of these management effects. In order to have an accurate assessment of a fund's management efficiency, we need to control for other factors that may also influence the fund's tracking ability, but are not under the full control and discretion of the fund's management. These other factors include the financing effect and the compounding effect.

\subsection{Management effects}

Similar to traditional (i.e., +1x) ETFs, investors of LETFs bear the explicit costs of managing the funds. The largest component of these costs is the investment advisory and management service fees charged by fund issuers, which are typically charged at annualized rates based on the fund's daily net asset values. The higher the expense ratio, the more an LETF is expected to underperform its underlying index. However, the expense ratio does not capture all the costs incurred in managing a fund. For example, transaction costs incurred by the fund in generating the target returns are not reflected in the fund's expense ratio. ${ }^{1}$ These costs are transaction fees for entering into and modifying derivative contracts, and are generally higher for

\footnotetext{
${ }^{1}$ The transaction costs we are referring to here are not the transaction costs (e.g., commissions and brokerage fees) paid by investors of LETFs in buying and selling units of LETFs on the exchanges.
} 
LETFs that: (1) track indices that are more volatile or less liquid; (2) have higher leverage ratios; and (3) have more frequent creation/redemption of their units. Further, there are transaction costs for buying and selling the underlying securities for LETFs that, in addition to entering into derivative contracts, also hold the underlying securities of the indices. ${ }^{2}$ It is not uncommon for bull LETFs tracking domestic equity indices to have a portion of their exposure invested in the constituent stocks of the indices. ${ }^{3,4}$ These LETFs incur transaction costs associated with matching the changes in the index weights and compositions. This type of transaction cost has been shown to be one of the factors that explain the tracking errors of traditional unleveraged equity-based ETFs and equity index funds in general (e.g., Elton, Gruber, Comer, and Li, 2002; Gastineau, 2002; Frino and Gallagher, 2002; Frino, Gallagher, Neubert, and Oetomo, 2004). Studies on traditional ETFs and index funds (e.g., Elton, Gruber, Comer, and Li, 2002; Frino, Gallagher, Neubert, and Oetomo, 2004) show that tracking errors can occur if dividends from the constituent stocks are accrued in a cash account before being distributed by the fund providers to the unit holders, resulting in an opportunity cost (for reinvestment). A similar cost can be expected to occur with bull LETFs that invest a portion of their exposures in the constituent stocks of the benchmark indices. This implicit cost is an increasing function of the dividend yield of the index, the amount of time delay of distribution, the contemporary return on the underlying index, and the leverage ratio. The effect, however, is unlikely to be economically significant since only a portion of the exposure is generated by holding the constituent stocks. More importantly, the distributable amounts of dividends from the funds are usually much less

\footnotetext{
${ }^{2}$ For equity LETFs, there are potential benefits for having part of the exposure in the form of a portfolio in the constituent stocks. For example, the fund issuer can generate income from lending the stocks in the portfolio. ${ }^{3}$ For example, in 2012, ProShares Ultra S\&P 500 generated its 200\% exposure to the S\&P 500 index by a combination of equity securities mimicking the composition of the index (73\%) and swaps and futures contracts (127\%). (May 2012).

${ }^{4}$ Unlike bull funds, most bear LETFs on equity indices use only derivative contracts to achieve the desired exposures.
} 
than the actual dividends received. Typically, any dividends or interests received by the funds are first used to offset the advisory and management service fees (on a daily basis) before being accrued and distributed to the unit holders (see ProShares, 2012).

The fund's choice of replication technique can also play a role in affecting its tracking errors. While the extensive use of derivative contracts (e.g., futures, forward, or swaps contracts) is expected to enable fund issuers to replicate the leverage returns reasonably accurately, there are risks associated with the use of derivatives (e.g., basis risks and correlation risks) that can cause mistracking. In addition, the use of a portfolio of derivatives (to diversify counterparty credit risks) may further increase the chance of deviation from the investment objective.

\subsection{Financing effect}

To generate leveraged returns, LETFs use leverage embedded in derivative contracts or (rarely) actual financial leverage. The performance of LETFs is affected by the financing costs associated with the leverage. Bull LETFs (i.e., funds with positive leverage multiples) have to acquire financing to leverage up their long positions. For example, to create two times the index return, a +2x LETF is effectively borrowing one time its exposure (via the counterparty of a derivative contract); whereas a $+3 x$ LETF is effectively borrowing two times its exposure to fulfill its leverage objective and thus incurring twice the financing costs as the $+2 \mathrm{x}$ LETF. Therefore, the higher the financing rate and the higher the leverage ratios, the more negatively performance will be affected by the financing effect. ${ }^{5}$ On the other hand, bear LETFs (i.e., funds with negative leverage multiples) hold short positions and benefit from this financing

\footnotetext{
${ }^{5}$ The financing rate is commonly benchmarked against the LIBOR rate.
} 
effect. ${ }^{6}$ The higher the financing rate and the larger the leveraged ratios, the more positively performance will be affected by the financing effect.

\subsection{Compounding effect}

Tracking errors can be caused by the effect of compounding of daily leveraged returns as the fund rebalances its exposure to the index daily so that the leverage ratio remains constant. The compounded return over a holding period longer than one day can deviate from the underlying index return multiplying by the promised leverage even if there is no tracking error on a daily basis. The magnitude and the direction of the deviation depend on the length of the holding period, the leverage ratio, and the return path of the underlying benchmark during that period.

Formally, it can be shown that (one plus) the compounded return of an LETF over $N$ days is: $^{7}$

$$
1+r_{t, t+N} \approx(1+\beta \bar{i}-k)^{N} \exp \left[-\frac{1}{2} \frac{\beta^{2}}{(1+\beta \bar{i}-k)^{2}} N s^{2}\right],
$$

where $r_{t, t+N}$ is the compounded return on the LETF over $N$ days, $\beta$ is the fund's leverage ratio, $\bar{i}$ is the arithmetic average of the index's daily return during the period, $s^{2}$ is the sample variance of the daily returns, and $k$ is the fund's daily costs and expenses (including any costs of financing and as a result of all management factors).

One can think of $1+r_{t, t+N}$ as the $N^{\text {th }}$-day value (i.e., the payoff) of a $\$ 1$ investment in the LETF. Equation (1) states that the payoff is equal to the leveraged compounded return based

\footnotetext{
${ }^{6}$ This argument is consistent with the fact that the counterparties of the derivatives transactions pass along the benefits from the short positions to the funds, which is confirmed by fund issuers such as ProShares (see Proshares, 2012).

${ }^{7}$ This approximation is adapted from Co (2009).
} 
on the average index daily return over the period, $\bar{i}$, multiplied by an exponential term. When there is volatility in the return path (i.e., $s>0$ ), the exponential term is less than one. The higher the volatility and the larger the magnitude of $\beta$, the lower will be the exponential term.

Therefore, given an average benchmark return, $\bar{i}$, the return on an LETF will be more negatively affected by daily compounding under more volatile return paths and the higher its leverage ratio. The return will be especially poor in a sideways market (i.e., when $\bar{i} \approx 0$ ).

\section{Sample description}

Our sample consists of funds tracking four major underlying indices in the US market the S\&P 500, NASDAQ 100, Russell 2000, and the Dow Jones Industrial Average. These four indices have well-established traditional $(+1 \mathrm{x})$ ETFs with large amounts of assets under management (AUM). Also, these indices are tracked by an inverse (i.e., -1x) ETF and every possible leveraged ETFs (i.e., $+2 x,-2 x,+3 x$, and $-3 x$ ). We therefore have a complete set of funds on which to estimate and compare tracking ability.

Table 1 displays the names and descriptions of the funds in our sample. In total, there are four non-leveraged (i.e., +1x) ETFs and twenty-six LETFs (including four inverse ETFs). As of the end of 2012, the twenty-six LETFs have a combined AUM of \$11 billion, which is over 70\% of the total AUM of all equity (i.e., domestic and foreign) LETFs in the US market. ${ }^{8}$

Insert Table 1 Here

The last column of Table 1 contains information on funds' net expense ratios in $2012 .{ }^{9}$

These ratios include the investment advisory and management service fees charged by fund issuers, and are expressed as percentages of the funds' net asset values. As reported, the net

\footnotetext{
${ }^{8}$ As of the end of 2012, there were approximately 160 equity leveraged ETFs traded in the US market, with aggregate AUMs of around $\$ 15$ billion.

${ }^{9}$ These ratios were essentially unchanged throughout our sample period.
} 
expense ratios for $+1 \mathrm{x}$ ETFs are all low (ranging from $0.09 \%$ to $0.20 \%$ per year). The expense ratios of LETFs are much higher (between $0.70 \%$ and $0.98 \%$ per year), reflecting the higher costs in managing LETFs and the fact that the asset base of these funds (on which management fees are calculated) is much smaller. However, the expense ratios of LETFs are in the same range regardless of the underlying indices, the magnitude of leverage, and whether the funds are bull or bear funds.

\section{A preliminary investigation}

As a preliminary step, we show how the funds' returns under various market conditions deviate from the stated multiples, and highlight the effects of compounding, financing, and other management factors on the deviations under those different market conditions. The funds' returns are calculated based on the changes in their NAVs, not the changes in their market prices. This approach is commonly used in studies that examine tracking errors of ETFs (e.g., Frino and Gallagher, 2001; Elton, Gruber, Comer, and Li, 2002; Gastineau, 2004). By adopting this approach, we make sure our tracking error analysis will not be contaminated by any pricing inefficiency of the market.

We compute the return deviations (i.e., tracking errors) of the funds in our sample over 6month holding periods starting either January 1st or July 1st of each year. We consider nonoverlapping holding periods within the common sample period of the funds that track the same underlying index. Therefore, the number of 6-month periods for each of our four groups of funds is dictated by the fund with the latest listing date (see Table 1) within each group. 
For the purpose of separating the compounding effect from the other factors, we use an approach similar to the one adopted by Shum and Kang (2013) and define tracking errors in two ways: ${ }^{10}$

$$
\begin{aligned}
& T E_{1, t, t+N}=r_{t, t+N}-I_{1, t, t+N}=r_{t, t+N}-\beta \cdot\left[\prod_{j=1}^{N}\left(1+i_{t+j-1, t+j}\right)-1\right], \\
& T E_{2, t, t+N}=r_{t, t+N}-I_{2, t, t+N}=r_{t, t+N}-\left[\prod_{j=1}^{N}\left(1+\beta \cdot i_{t+j-1, t+j}\right)-1\right],
\end{aligned}
$$

where $N$ is the length of the holding period, $\beta$ is the fund's leverage ratio, $i_{t-1, t}$ is the index return between day $t-1$ and day $t$, and $r_{t, t+N}$ is the holding-period return on the NAV of the LETF, that is: ${ }^{11}$

$$
r_{t, t+N}=\frac{N A V_{t+N}}{N A V_{t}}-1
$$

As defined, $T E_{1}$ measures the difference between the fund's holding-period return and the multiple of the underlying index's return over the same period. $T E_{1}$ encompasses tracking errors that can occur from management factors, financial costs, and compounding. The second term on the right-hand side of Equation (2) is what most investors assume (incorrectly) they will get from investing in an LETF. Accordingly, $T E_{1}$ is the definition of tracking errors that most investors have in mind.

On the other hand, $T E_{2}$ measures the difference between the fund's holding-period return and what the fund's compounded return would be if there were no tracking error in the daily returns (i.e., if there were no management factors or financing effects and so the fund's return

\footnotetext{
${ }^{10}$ Focusing on the recent financial crisis, Shum and Kang (2013) disentangle the effects of compounding and management factors on the performance of a sample of LETFs on commodities, domestic and international equity indices over the period of 2008-2009.

${ }^{11}$ The NAVs used in this calculation are adjusted for dividend and capital-gain distributions that an ETF made to its investors during the sample period. The distributions are added back to the NAVs before we calculate the return in Equation (4).
} 
exactly matched the promised return on every day during the period). In other words, the second term on the right-hand side of Equation (3) captures the effect of compounding when leverage is used. Accordingly, $T E_{2}$ measures errors caused by how the fund is managed and financing costs. Both tracking errors are expected to increase with the length of holding period $N$, while $T E_{1}$ will also be sensitive to the return path that the underlying benchmark takes during the holding period. As illustrated in Section 2.3, $T E_{1}$ is expected to be more negative in a sideways market and when realized volatility is high.

We report in Table 2 the tracking errors of the funds tracking the S\&P 500 index over 6month holding periods constructed above. In columns 2 and 3 of Table 2, we also report the arithmetic mean and standard deviation of the daily returns on the S\&P 500 index during the corresponding 6-month period. Consider first the measure $T E_{2}$ (reported in Panel B of Table 2). $T E_{2}$ is negative for virtually all 6-month holding periods of all the funds. That is, the funds typically underperform the benchmark index based on $T E_{2}$, regardless of their leverage ratios. This underperformance is not surprising given that the dominant management factor is the advisory and management service fees, which reduce the funds' returns relative to their benchmark index. Not surprisingly, $T E_{2}$ is much lower for the traditional $+1 x$ ETF (i.e., SPY) than for the inverse or leveraged ETFs. This observation is consistent with the fact that SPY has the lowest net expense ratios (see Table 1).

\section{Insert Table 2 Here}

There are a couple of noteworthy patterns in observing the funds' $T E_{2}$. First, except for SPXL and SPXS, bull LETFs have more negative $T E_{2}$ than their bear counterparts, even though they have essentially the same expense ratios. For example, the median $T E_{2}$ of SSO $(\mathrm{a}+2 \mathrm{x}$ LETF) is $-0.74 \%$, while that of SDS (a -2x LETF) is $-0.30 \%$. Again, even though they have 
essentially identical expense ratios, $T E_{2}$ tends to be more (less) negative for bull (bear) LETFs when leverage ratio increases. ${ }^{12}$ For example, the median $T E_{2}$ for SSO (a $+2 x$ LETF) is $-0.74 \%$, while that of UPRO (a +3x LETF) is $-1.07 \%$. On the other hand, the median $T E_{2}$ for SDS (a $-2 \mathrm{x}$ LETF) is $-0.30 \%$, while that of SPXU (a -3x LETF) is only $-0.24 \%$.

These observed patterns can be explained by the financing costs associated with generating the target leverage return. As mentioned in Section 2.2, the financing effect lowers (enhances) the return on bull (bear) LETFs, thus making their tracking errors more (less) negative. In addition, because the financing effect is amplified by the leverage of the funds, the returns on bull (bear) LETFs with higher leverage are reduced (enhanced) by a larger amount than their lower-leverage counterparts.

Let us now turn our attention to $T E_{1}$ (reported in Panel A of Table 2). Recall that $T E_{1}$ captures tracking errors caused by all factors. Comparing with $T E_{2}, T E_{1}$ is much more volatile over time. With respect to its magnitude, $T E_{1}$ is generally much larger than $T E_{2}$, which suggests that the compounding effect normally dominates all other factors in dictating the sign and magnitude of the tracking error. Compounding can materially affect the realized returns on the NAVs of LETFs in either a positive or negative fashion.

For the same 6-month period, all LETFs have essentially the same sign of $T E_{1}$ regardless of whether it is a bull or bear fund. As illustrated in Section 2.3, the market condition during the holding period can affect the holding-period return of LETFs. In particular, a trending (sideways) market together with low (high) return volatility result in positive (negative) compounding effect and thus a positive (negative) impact on $T E_{1}$ for both bull and bear LETFs. Since the compounding effect is magnified by the leverage of the LETF, the higher the leverage, the larger the impact is on $T E_{1}$. The switching of the sign of $T E_{1}$ from period to period can be

\footnotetext{
${ }^{12}$ But again, the behavior of SPXL and SPXS does not conform to this pattern.
} 
explained by the difference in market conditions from one period to the other. For example, among all the 6-month periods under consideration, all LETFs realize their most positive $T E_{1}$ during the period from July to December of 2010. This strong positive effect can be attributed to the favorable return paths (i.e., a trending market together with a reasonably low return volatility) realized by the S\&P 500 index during these six months (see Columns 2 and 3). Both bull and bear funds benefited from this positive compounding effect and the effect is stronger for LETFs with higher leverage.

On the contrary, a sideways market (i.e., close to zero average returns) together with high return volatility is the recipe for negative compounding effect. Consider the period from July to December of 2011. During this period, the S\&P 500 index fluctuated substantially but ended up with only a slightly negative return. Therefore, it is not surprising that we witness the most negative $T E_{1}$ for all LETFs (whether bulls or bears) being realized during this period. Again, the effect is stronger for LETFs with higher leverage.

To conserve space, we do not report the results for funds tracking the other three benchmark indices. ${ }^{13}$ The above mentioned patterns are also observed for our sample of funds tracking the NASDAQ 100 index and the Dow Jones Industrial Average. However, these patterns are not observed for funds tracking the Russell 2000 index. For this group of funds, we conjecture that, apart from the compounding effect, the advisory/management service fees and financing costs, other management factors (e.g., transaction costs and replication approach) also play important roles in affecting their tracking errors.

The above preliminary analysis allows us to examine a number of characteristics of the management, financing, and compounding effects and their impact on holding-period returns on LETFs. However, to evaluate the effectiveness of a fund's management, an investor may want to

\footnotetext{
${ }^{13}$ The results for these funds are available from the authors.
} 
answer the following: Which fund has the most favorable (i.e., least negative) "alpha"? Which fund is able to generate the most accurate "beta" (i.e., the promised leverage multiple)? How do the "alpha" and "beta" vary with the length of the holding period? To address these questions and concerns, we propose a new method to measure tracking errors for LETFs. It involves regression analysis that allows us to control for the effects of compounding and financing on tracking errors.

\section{Regression analysis}

\subsection{Proposed regression technique}

Studies of traditional (+1x) ETFs employ a few approaches to measure funds' tracking errors, one of which is regression analysis where a fund's returns (based on its NAVs) are regressed on the underlying index's returns (e.g., Elton, Gruber, Comer, and Li, 2002; Frino, Gallagher, Neubert, and Oetomo, 2004). Existing studies on LETFs also adopt this regression approach where the regression equation is specified as:

$$
r_{t, t+N}=a+b \cdot\left[\prod_{j=1}^{N}\left(1+i_{t+j-1, t+j}\right)-1\right]+e_{t},
$$

where, as defined earlier, $r_{t, t+N}$ is the $N$-day holding-period return on the NAV of an LETF, $i_{t-1, t}$ is the index return between day $t-1$ and day $t$, and $e_{t}$ is the residual term (see, for example, Lu, Wang and Zhang, 2009; Charupat and Miu, 2011, 2013; and Shum and Kang, 2013). An estimated intercept (a) that is close to zero together with an estimated slope coefficient $(b)$ that is close to the fund's stated leverage ratio $(\beta)$ are considered indicators of superior tracking ability. On the other hand, any significant difference between $b$ and $\beta$ is interpreted as the fund's inability to generate the promised leveraged return. 
The problem with this conventional approach is that tracking errors can be caused by both compounding and other factors, while the use of a single explanatory variable in Equation (5) does not allow us to disentangle the different sources of errors. Consequently, the effect of all the different factors mentioned in Section 2 can show up in both the intercept and the slope coefficient, making it difficult to interpret the regression results. For example, because of the compounding effect, the estimated value of $b$ may be different from the fund's leverage ratio $\beta$ even if management is cost effective and is doing a perfect job in replicating the leveraged return. The impact of the compounding effect is expected to be particularly strong for long holding periods, for LETFs with high leverage ratios, and for bear LETFs (as opposed to bull LETFs). ${ }^{14}$

To control for the compounding effect, we propose a new regression method as follows. First, by modeling $T E_{2}$ as the sum of a constant $(\alpha)$ and a random component $\left(e_{t}\right)$, we obtain the following equation by rearranging Equation (3).

$$
r_{t, t+N}=\alpha+\left[\prod_{j=1}^{N}\left(1+\beta \cdot i_{t+j-1, t+j}\right)-1\right]+e_{t} .
$$

We expand the second term on the right-hand side of Equation (6) to obtain: ${ }^{15}$

$$
\begin{aligned}
r_{t, t+N}= & \alpha+\beta \cdot\left[\prod_{j=1}^{N}\left(1+i_{t+j-1, t+j}\right)-1\right]+\left(\beta^{2}-\beta\right) \cdot\left[\sum_{1 \leq k_{1}<k_{2} \leq N}\left(i_{t+k_{1}-1, t+k_{1}} \cdot i_{t+k_{2}-1, t+k_{2}}\right)\right] \\
& +\cdots+\left(\beta^{m}-\beta\right) \cdot\left[\sum_{1 \leq k_{1}<k_{2}<\cdots<k_{m} \leq N}\left(i_{t+k_{1}-1, t+k_{1}} \cdot i_{t+k_{2}-1, t+k_{2}} \cdot \ldots \cdot i_{t+k_{m}-1, t+k_{m}}\right)\right] \\
& +\cdots+\left(\beta^{N}-\beta\right) \cdot\left[i_{t, t+1} \cdot i_{t+1, t+2} \cdot \ldots \cdot i_{t+N-1, t+N}\right]+e_{t}
\end{aligned}
$$

\footnotetext{
${ }^{14}$ Bear funds are subject to stronger compounding effect than bull funds. See Equation (7) and the discussion below.

${ }^{15}$ We obtain Equation (7) from Equation (6) by comparing the coefficients of the corresponding terms of the two polynomials obtained from expanding the compounded returns $I_{1}$ and $I_{2}$ in Equations (2) and (3), respectively. Details of the derivation are available from the authors.
} 
Unlike Equation (5), in which only the first-order term of index return is considered, Equation (7) incorporates also the higher-order terms, which together capture the compounding effect. The intercept and the first slope coefficient (i.e., $\beta$ ) of Equation (7) can now serve as cleaner measures of the fund's tracking ability that are free of compounding effects.

There are altogether $N$-1 higher-order terms in Equation (7) with slope coefficients of increasing magnitude that is governed by the leverage ratio. Although the magnitude of the coefficient $\left(\beta^{m}-\beta\right)$ and the number of cross product terms in the summation in the square bracket of each term of Equation (7) increases with its order $m$, the magnitude of the term diminishes quickly with increasing order. ${ }^{16}$ The second-order term therefore captures most of the compounding effect. A more careful examination of the second-order term reveals that it measures the autocorrelation of underlying index returns. A "trending" ("sideways") market tends to have positively (negatively) autocorrelated returns and thus a positive (negative) secondorder term. Together with the positive slope coefficient of the second-order term (i.e., $\beta^{2}-\beta>0$ regardless of whether $\beta$ is positive or negative), a "trending" ("sideways") market will likely result in positive (negative) compounding effect on the returns on both bull and bear LETFs, as illustrated previously based on the results reported in Table $2 .{ }^{17}$ The slope coefficient of the second-order term represents the exposure of LETF investors to autocorrelation effect.

Further simulation analysis (not reported) suggests that we can ignore terms of order higher than the 3rd-order term without affecting the accuracy of tracking error analysis for most

\footnotetext{
${ }^{16}$ When the order $m$ increases, (1) the coefficient is growing at the rate of $\beta^{m}$; (2) the number of cross product terms is growing at the rate of $N^{m}$; and (3) the magnitude of each cross product term is growing at the rate of $i^{m}$. Thus, as far as the product $\beta \times N \times i$ is smaller than unity, the magnitude of the term decreases when $m$ increases. Since $\beta \times N \times i$ is similar to the leveraged return on the underlying index over the holding period from $t$ to $t+N$, it is likely to be much smaller than unity (i.e., $100 \%$ ) even for a one-year holding period.

${ }^{17}$ Note that $\beta^{2}-\beta$ is greater when $\beta$ is negative (i.e., bear funds) than when $\beta$ is positive (bull funds). As a result, the effect of compounding is stronger for bear funds than bull funds.
} 
practical purposes. ${ }^{18}$ We conduct our subsequent regression analysis for our sample of LETFs using only three terms; i.e.,

$$
\begin{aligned}
r_{t, t+N}= & a+b_{1} \cdot\left[\prod_{j=1}^{N}\left(1+i_{t+j-1, t+j}\right)-1\right]+b_{2} \cdot\left[\sum_{1 \leq k_{1}<k_{2} \leq N}\left(i_{t+k_{1}-1, t+k_{1}} \cdot i_{t+k_{2}-1, t+k_{2}}\right)\right] \\
& +b_{3} \cdot\left[\sum_{1 \leq k_{1}<k_{2}<k_{3} \leq N}\left(i_{t+k_{1}-1, t+k_{1}} \cdot i_{t+k_{2}-1, t+k_{2}} \cdot i_{t+k_{3}-1, t+k_{3}}\right)\right]+e_{t}
\end{aligned}
$$

If the estimated values of $a$ and $b_{1}$ are close to zero and the stated leverage ratio $\beta$ respectively, we will conclude that the fund under consideration is efficient in delivering the promised leveraged return.

\subsection{Regression results}

\subsubsection{Conventional regression approach}

Before presenting the results from our proposed regression method, we conduct the regression analysis for all the funds in our sample following the conventional regression approach (i.e., Equation (5)). It serves as the benchmark when we examine the regression results from our proposed method. We run regressions based on one-week, one-month, and one-quarter holding periods, respectively. For brevity, we present in Table 3 only the results for the funds that are based on the S\&P 500 index. ${ }^{19}$ In conducting the regressions, we use the common data period from June 23, 2009 to December 31, 2012 for all the 10 funds in our sample that are tracking the S\&P 500 index. We use overlapping weekly returns to generate returns for holding periods of one month (four weeks) and one quarter (12 weeks). The Newey-West procedure is

\footnotetext{
${ }^{18}$ The results of the simulation analysis are available from the authors.

${ }^{19}$ The following illustrations and discussions are equally applicable to funds based on the other three benchmark indices. The regression results for these funds are available from the authors.
} 
used to calculate the standard errors of the estimates for the regressions involving overlapping observations. $^{20}$

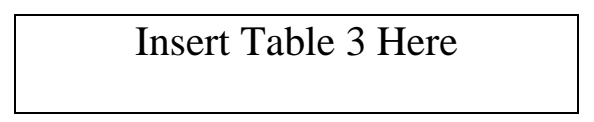

Consider, for example, the regression estimates for SPXU (i.e., a -3x fund) for the holding period of one quarter. The estimated intercept is -0.0313 , suggesting an average return shortfall of $3.13 \%$ per quarter, while the slope coefficient is -2.495 , which is significantly different from the promised leverage ratio of -3 at the $1 \%$ confidence level. However, the regression does not tell us how much of the return shortfall and how much of the slope coefficient deviation can be attributed to the compounding effect. By not being able to control for the compounding effect, it does not facilitate the comparison of cost effectiveness among different LETFs. For example, by only looking at the quarterly regression results of Table 3, a market participant, who is not fully aware of the compounding effect, may naively conclude that the cost effectiveness and the tracking ability of SPXU are much worse than those of UPRO given the fact that: (1) the estimated intercept of the former (i.e., -0.0313) is more negative than that of the latter (i.e., -0.0154); and (2) the estimated slope coefficient of the former (i.e., -2.495) is more deviated from its leverage ratio of -3 than that of the latter (i.e., 3.140) from its ratio of 3. In fact, since the compounding effect is stronger for bear funds than bull funds of the same leverage magnitude, the intercept of SPXU being more negative than that of UPRO does not necessarily mean that the former is indeed managed less efficiently. The larger return shortfall of the former may be fully attributable to the stronger compounding effect. We cannot disentangle the compounding effect in conducting the conventional regression analysis. As

\footnotetext{
${ }^{20}$ The use of overlapping observations can cause the OLS parameter estimates to be inefficient and hypothesis tests biased (Hansen and Hodrick, 1980). In the literature, the Newey-West approach is commonly used to correct this bias. However, Harri and Brorsen (2009) show that the Newey-West approach tends to underestimate the standard deviations of the estimates, and thus causes the null hypothesis to be rejected too often. The bias could be large when the sample size is small. Although our sample is not small, it is possible that the problem exists.
} 
subsequent analysis using our proposed methodology will reveal, SPXU is more cost effective than UPRO over our sample period after controlling for the difference in the compounding effect (see discussion below).

Let us examine a pair of funds with different magnitude of leverage ratios. From the quarterly regression results presented in Table 3, the average return shortfall of RSW (a -2x LETF of S\&P 500) is 1.56\%/quarter which is more than twice that of SH (the inverse ETF of S\&P 500). Without further analysis, it is hard to tell if this poor performance of RSW is indeed the direct result of factors related to its management and financing or is simply due to the compounding effect, which we know is more significant for higher-leverage LETFs. As subsequent analysis using our proposed methodology will reveal, the cost effectiveness of these two funds is actually quite similar after we control for the difference in compounding effect (see discussion below).

\subsubsection{Proposed regression approach}

To demonstrate our proposed approach, we run the regression of Equation (8) for our sample of 30 funds based on one-week, one-month, and one-quarter holding periods respectively. There is no compounding effect in daily returns, so we do not run the regression with a one-day holding period. We do not conduct the regression for a one-year holding period since the regression results are not expected to be informative given the possibility of multicollinearity due to the high correlations among the right-hand-side variables of Equation (8). To compare the regression results across funds tracking the same underlying benchmark, we use a common data period for all the funds within each group, which starts from the listing date (see Table 1) of the fund most recently introduced to the market and ends on December 31, 2012. 
As the LETFs in our sample do not have a long history, we use overlapping, weekly returns to generate returns for holding periods of one month (four weeks) and one quarter (12 weeks). Similar to the conventional regression analysis conducted previously, the Newey-West procedure is used to calculate the standard errors of the estimates for the regressions involving overlapping observations.

We test whether the intercept $(a)$ is different from zero, and whether the three slope coefficients $\left(b_{1}, b_{2}\right.$, and $\left.b_{3}\right)$ are different from their theoretical values of $\beta, \beta^{2}-\beta$, and $\beta^{3}-\beta$ respectively according to the fund's leverage ratio. We present the results in Table 4.

Insert Table 4 Here

Consider first the estimated intercepts. Not surprisingly, all of them are negative given the management fees and expenses. Except for SPXS and IWM, the intercepts for all holding periods of all the funds are statistically significant (at least at the $5 \%$ level). Comparing the intercepts of the same fund across holding periods, the average "loss rate" due to management factors and financing effect is in general uniform. For example, the estimated intercept of the one-quarter holding period regression of QLD is -0.32\%, which is approximately three (twelve) times that of the estimated intercept of the one-month (one-week) holding period regression of QLD (see Table 4, Panel B).

Comparing the intercepts of different LETFs for a given holding period, we see that they have very different average "loss rates", despite the fact that all the LETFs in our sample have very similar expense ratios. This observation suggests that, besides the size of the expense ratio, other management factors and the financing effect also come into play in affecting the degree of underperformance of the LETFs with respect to the benchmark indices. 
There are a few noteworthy patterns. First, for funds tracking the S\&P 500 index, NASDAQ 100 index, and the Dow Jones Industrial Average, bull LETFs always underperform by more than their bear counterparts. For example, the intercept term in the quarterly return regression of SSO $(\mathrm{a}+2 \mathrm{x}$ LETF of S\&P 500) is $-0.32 \%$, while that of SDS (a -2x LETF of S\&P 500) is only $-0.19 \%$ (see Table 4, Panel A). This observation is consistent with the asymmetric effect of financing costs on bull vs. bear funds. The return on the former is negatively affected by the financing costs, while that of the latter benefits from the costs. This effect therefore increases (lessens) the underperformance of bull (bear) LETFs. We do not observe this pattern for the funds tracking the Russell 2000 index (see Panel C). It is possible that other management factors (e.g., transaction costs and replication errors) might have dominated the financing effect for these LETFs.

Second, almost without any exceptions, the higher the leverage ratio, the larger is the underperformance (i.e., the more negative is the intercept term) of the LETF ceteris paribus. This finding is consistent with the fact that transaction costs tend to be higher in managing LETFs with higher leverage ratios. ${ }^{21}$

By being able to control for the compounding effect, our proposed regression approach allows for the direct comparison of cost effectiveness among different LETFs. The conventional regression approach, on the other hand, does not readily lend itself to such a comparison. Recall our previous discussion on the conventional regression results of SPXU vs. UPRO. By simply comparing the respective estimated intercepts (-0.0313 vs. -0.0154) from the conventional (quarterly) regressions of these two funds as presented in Table 3, an unsophisticated market participant, who is not fully aware of the compounding effect, may naively conclude that the cost

\footnotetext{
${ }^{21}$ For bull LETFs, this observed relation between leverage ratio and underperformance may also be explained by financing costs. Financing costs incurred in generating the leverage exposure increase with the leverage ratio, thus further contributing to the underperformance of highly leveraged bull funds.
} 
effectiveness of SPXU is worse than that of UPRO. But the larger return shortfall of the former may be fully attributable to the fact that it is subject to a stronger compounding effect. Our proposed regression approach allows us to more easily arrive at an apple-to-apple comparison in measuring cost effectiveness. Based on the quarterly regression results of these two funds as reported in Table 4, Panel A, after controlling for the compounding effect, SPXU actually has a smaller average return shortfall than UPRO given its less negative estimated intercept (i.e., 0.0023 vs. -0.0048 ). Our proposed approach therefore allows us to arrive at the correct conclusion that SPXU was actually more cost effective than UPRO over our sample period.

We can use the regression results for LETFs of different leverage ratios to further illustrate the benefit of screening out the compounding effect in comparing cost effectiveness. Recall our previous discussion on the conventional regression results of RSW vs. SH. According to the quarterly regression results, the average return shortfall of the former is more than twice that of the latter based on their respective estimated intercepts. However, it is hard to tell to what extent this poor performance of RSW is a direct result of the stronger compounding effect that we expect for higher-leveraged LETFs. With our proposed regression results, we can easily tell that the portion of the average return shortfall of RSW that is attributable to management factors and financing effect is actually slightly smaller than that of SH. Based on the estimated intercepts of the quarterly regression results presented in Table 4 Panel A, after controlling for the compounding effect, the average return shortfalls are $0.13 \%$ and $0.17 \%$ per quarter for RSW and $\mathrm{SH}$, respectively. By comparing the quarterly regression results for RSW presented in Tables 4 and 5, we notice that management factors together with financing effect account for a small fraction of the total return shortfall of $1.56 \%$ per quarter (Table 3) for RSW. Most of the return shortfall is the result of the compounding effect. 
Next, consider the estimates for the slope coefficients based on our proposed regression approach. In Table 4, even though quite a number of the first slope coefficient estimates (i.e., $b_{1}$ ) are statistically different from the corresponding leverage ratios, most of the deviations are not considered to be economically significant. In other words, the funds are in general quite accurate in replicating the promised multiple returns. However, there are indications that the performance in leverage replication worsens as holding period lengthens. It seems that the daily errors resulting from the process of generating the required leverage are not random and thus not able to offset each other over time. This results in a systematic bias in the leverage which becomes more pronounced over long holding periods.

We notice two other patterns regarding $b_{1}$ : (1) Bear LETFs tend to deviate more from their leverage ratios than their bull counterparts; and (2) LETFs with higher leverage tend to have $b_{1}$ that deviate more from the promised leverage ratios. These two observations are consistent with the notion that it is generally more difficult to accurately replicate leveraged returns for bear LETFs and for funds with high leverage ratios. The generally higher transaction costs involved in these kinds of LETFs make it more difficult for management to deliver the promised returns.

By comparing the slope coefficients reported in Table 3 and Table 4, Panel A (i.e., $b$ vs. $b_{1}$ ), we can also quantify the relative importance of the compounding effect and all other factors in causing the deviation from the stated leverage ratio. Let us examine the quarterly regression results for SDS as an example. With the proposed regression results, we now know that it is the compounding effect rather than the management factors or the financing effect that contributes more to the deviation of the slope coefficient (b) of -1.760 (see Table 3) from the promised multiple of -2. The deviation solely due to management factors together with financing effect is 
found to be much smaller based on the corresponding slope coefficient estimate $\left(b_{1}\right)$ of -1.995 in Table 4, Panel A. By comparing the estimates of $b_{1}$ of Table 4, Panel A with the corresponding estimates of $b$ in Table 3, we find that it is almost always the case that the deviations in the slope coefficients are predominantly the result of the compounding effect rather than other factors for holding period even as short as one week.

Finally, let us turn to the estimated slope coefficients of the second- and third-order terms (i.e., $b_{2}$ and $b_{3}$ ) of Equation (8). Recall that they capture the exposure of the funds' returns to the autocorrelation effects of underlying index returns. For the holding period of one week, the majority of the estimates of $b_{2}$ and $b_{3}$ are not statistically different from their theoretical values of $\beta^{2}-\beta$ and $\beta^{3}$ - $\beta$ respectively. As the holding period lengthens to one month and one quarter, the estimates of $b_{2}$ and $b_{3}$ tend to deviate more from their theoretical values. These results suggest the existence of (non-random) management factors that result in deviations from the expected sensitivities of a fund's returns to these higher-order terms. ${ }^{22}$ Nevertheless, compared to $b_{1}$, these higher-order slope coefficients have larger standard errors and are more difficult to estimate accurately.

\subsubsection{Controlling for the financing effect in regression analysis}

As discussed in Section 2.2, the performance of an LETF is affected by the financing costs associated with the use of derivative contracts (e.g., total return swap contracts) in generating the target leveraged exposure. Financing costs exert opposite effects on the

\footnotetext{
${ }^{22}$ For example, the existence of transaction costs may distort the sensitivity of an LETF's returns on the autocorrelation of underlying index returns. LETFs need to rebalance exposures at the end of each day to maintain the constant leverage ratios. It is quite likely that, the larger the required end-of-day exposure adjustment, the more transaction costs will be incurred on that day. Given that the amount of the daily exposure adjustment is a function of the contemporary daily return on the underlying index (see e.g., Cheng and Madhavan, 2009), the amount of transaction costs incurred will also be related to the underlying index returns. Given this non-random relation between transaction costs and index returns, the autocorrelation of returns before and after netting out the transaction costs could be very different and thus may result in a bias in the coefficients of the higher-order terms.
} 
performance of bull vs. bear funds. Given that bull LETFs are incurring financing costs in leveraging up their returns, the higher the reference interest rate (i.e., LIBOR) and the larger the leveraged ratios, the more negatively performance will be affected by the financing effect. On the other hand, bear LETFs hold short positions and benefit from this financing effect. The higher the reference interest rate and the larger the leveraged ratios, the more positively performance will be affected by the financing effect. The financing cost can be expressed as $(\beta-1) \times$ LIBOR . For example, the swap counterparty of a $+3 x$ LETF (i.e., $\beta=3$ ) needs to effectively borrow two times (i.e., $\beta-1=3-1=2$ ) the exposure in order to deliver three times the benchmark returns. The swap counterparty of a -3x LETF, on the other hand, is effectively shorting three times the exposure and thus earning interests on four times (i.e., $\beta-1=-3-1=-4$ ) the asset value. Therefore, it incurs a negative financing cost.

To a large extent, the financing effect is beyond the control of the fund issuer and thus does not directly reflect the skill of the management. To be more definite in our assessment of management efficiency, we need to control for any difference in the financing effect on different types of LETFs. We run the following panel regression of the NAV returns using all the 30 funds in our sample to explicitly control for both the compounding and financing effects: ${ }^{23}$

$$
\begin{aligned}
& r_{s, t, t+N}=a_{s}+\gamma_{1} \cdot\left\{\beta_{s} \cdot\left[\prod_{j=1}^{N}\left(1+i_{t+j-1, t+j}\right)-1\right]\right\}+\gamma_{2} \cdot\left\{\left(\beta_{s}^{2}-\beta_{s}\right) \cdot\left[\sum_{1 \leq k_{1}<k_{2} \leq N}\left(i_{t+k_{1}-1, t+k_{1}} \cdot i_{t+k_{2}-1, t+k_{2}}\right)\right]\right\} \\
& +\gamma_{3} \cdot\left\{\left(\beta_{s}^{3}-\beta_{s}\right) \cdot\left[\sum_{1 \leq k_{1}<k_{2}<k_{3} \leq N}\left(i_{t+k_{1}-1, t+k_{1}} \cdot i_{t+k_{2}-1, t+k_{2}} \cdot i_{t+k_{3}-1, t+k_{3}}\right)\right]\right\}+\gamma_{r} \cdot\left\{\left(\beta_{s}-1\right) \cdot L I B O R_{t, t+N}\right\}+e_{t}
\end{aligned}
$$

where $s$ ( $=1$ to 30 ) denotes each of the 30 funds and $\beta_{s}$ is the leverage ratio of fund $s . L I B O R_{t, t+N}$ is the average three-month LIBOR rate over the time period from $t$ to $t+N$. The second and third

\footnotetext{
${ }^{23}$ We thank an anonymous referee for suggesting the use of a control variable to capture the financing effect in the regression analysis.
} 
right-hand side variables of Equation (9) together capture the compounding effect. The summation terms within the square brackets of the second and third variables are the same as the explanatory variables in Equation (8). The fourth right-hand side variable of Equation (9) captures the financing costs of different LETFs. We conduct the regression over the sample period from the inception date of the most recently introduced LETF (i.e., February 2010) to December 2012. We expect the coefficients $\gamma_{1}, \gamma_{2}$, and $\gamma_{3}$ to be close to unity if the funds can closely replicate the respective leveraged returns in a compounded fashion. On the other hand, a negative estimated value of $\gamma_{r}$ will confirm the significance of the financing effect. The intercepts $a_{s}$ measure fund performance after screening out both the compounding and financing effects. To conserve space, we present in Table 5 only the panel regression results for quarterly holding period returns. ${ }^{24}$

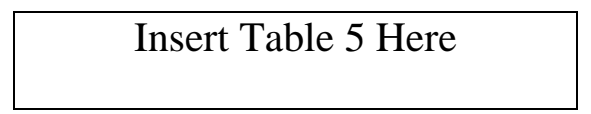

We conduct three different versions of the regression. In Regression (i), we consider only the linear effect of the benchmark index return (i.e., only using the first explanatory variable of Equation (9)), thus ignoring both the compounding and financing effects. Not surprisingly, the estimated value of $\gamma_{1}(0.935)$ is quite different from unity under this specification since the compounding effect is ignored. Besides, most of the estimated intercepts in Regression (i) are negative and are both statistically and economically significant. For example, based on the estimated intercept, the average return shortfall of UPRO is about 77.2 basis points (bps) per quarter. Bear funds tend to have more negative intercepts than bull funds, whereas the estimated intercepts are in general more negative for funds with higher leverage

\footnotetext{
${ }^{24}$ The results for weekly and monthly holding period regressions are qualitatively the same as those of the quarterly holding period regressions. The regression results are available from the authors.
} 
ratio. This finding is consistent with our expected effect of compounding, which is stronger for bear funds and for funds with higher leverage ratios.

In Regression (ii), we cater for the compounding effect by including the first three explanatory variables of Equation (9). As expected, comparing with that of Regression (i), the estimated value of $\gamma_{1}(0.997)$ becomes closer to unity, albeit the difference is still statistically significant. The coefficients for the higher-order terms (i.e., $\gamma_{2}$ and $\gamma_{3}$ ) of the benchmark index returns are also close to 1 . Not surprisingly, the estimated intercepts become less negative after we appropriately cater for the compounding effect. For example, based on the estimated intercept of Regression (ii), the average return shortfall of UPRO is only 42.9 bps per quarter. Comparing with the corresponding result of Regression (i) mentioned above, we conclude that compounding effect accounts for 34.3 bps (= 77.2 - 42.9) of the total average return shortfall of 77.2 bps. After correcting for the compounding effect, the relation between leverage ratio and the magnitude of the intercept estimate previously observed in Regression (i) mostly subsides. Again, unlike in Regression (i), we now do not observe a clear pattern that bear funds tend to have more negative intercepts than bull funds, ceteris paribus. For example, from Regression (i), the intercept estimates of UPRO ( $a+3 x$ LETF) and SPXU ( $a$-3x LETF) are -77.2 and -243.1 bps, respectively. In Regression (ii), on the contrary, the intercept estimate of UPRO (-42.9 bps) becomes more negative than that of SPXU (-20.3 bps). After controlling for the compounding effect, we conclude that the performance of UPRO is more negatively affected by the combined effect of financing and management factors than that of SPXU. Based on the negative intercept estimates, all 26 LETFs in our sample underperform the respective benchmark index returns. How significant is the financing effect in explaining the performance of LETF? We can shed some light on this issue by examining the results of Regression (iii) in Table 5. Regression 
(iii) is our full model that accounts for both the compounding and financing effects. It incorporates all the explanatory variables of Equation (9). First, the estimated value of $\gamma_{r}$ is indeed negative and is statistically significant at the $1 \%$ level, which confirms the significance of the financing effect on the NAV returns of LETFs. The coefficient estimates of $\gamma_{1}, \gamma_{2}$, and $\gamma_{3}$ are essentially identical to those of Regression (ii), suggesting that the compounding effect remains robust regardless of whether we explicitly model for the financing effect or not. Nevertheless, the financing effect does have a material impact on the intercept estimates. Specifically, comparing with the respective results of Regression (ii), the intercept estimates of bull funds become less negative, while those of bear funds become more negative. This is consistent with the asymmetric impact of the financing effect on bull vs. bear funds as discussed in Section 2.2. Recall that financing effect results in a cost for bull LETFs while benefiting bears. Therefore, when we appropriately account for the financing effect by adding the fourth explanatory variable in Equation (9) and thus remove its effect from the intercepts of the regression, we expect the intercepts of the bull (bear) funds to become less (more) negative. The difference between the corresponding intercept estimates of Regressions (ii) and (iii) represents the size of the financing effect. For example, out of the total average return shortfall of 42.9 bps per quarter (Regression (ii)) for UPRO, financing costs account for 6.2 bps (= 42.9 - 36.7). The remaining 36.7 bps shortfall is the result of purely management factors. We expect the most significant component of these management factors being the investment advisory and management service fees charged by the fund issuer. It is interesting to note that the 36.7 bps shortfall per quarter is indeed only slightly more than one fourth of the annual net expense ratio of 95 bps for UPRO.

Finally, in comparing the intercept estimates of Regression (iii) for LETFs tracking the same index, we notice that the underperformance of the funds tends to be larger the higher the 
leverage ratio. The lower management efficiency of the higher leveraged LETFs may be explained by the higher transaction costs and the increase in difficulty in replicating the leveraged returns for these funds.

\section{Conclusions}

We propose a new method to measure the tracking errors of leveraged exchange-traded funds (LETFs). Unlike the conventional regression analysis commonly used to measure the tracking errors of traditional (unleveraged) exchange-traded funds, the proposed method allows us to screen out the compounding effect of daily returns in measuring how close the LETFs are in tracking the promised leveraged returns on the underlying indices over different holding periods. We consider an extension of our proposed method that allows us to also control for the effect the necessary financing requirement of LETFs has on their performance. In doing so, we can isolate the effect due to management factors, allowing us to assess and compare the management efficiency of different LETFs.

Using the proposed methodology, we conduct an empirical analysis using a sample of the most liquid equity-based LETFs in the U.S. market tracking the S\&P 500, NASDAQ 100, Russell 2000, and the Dow Jones Industrial Average indices. Our results suggest that the compounding effect can significantly hinder the tracking ability of LETFs, especially for funds with high leverage ratio and as the holding period lengthens. The effect on the performance of the LETFs is conditional on the return path realized by the underlying index during the holding period. In particular, a "trending" underlying index with low return volatility enhances the holding-period performance of LETFs; whereas a "sideways" market with high return volatility exerts a negative effect on LETFs' performance. In general it is the compounding effect rather 
than the management factors or the financing effect that plays a more important role in dictating the tracking ability of an LETF, especially as the holding period lengthens.

After screening out the compounding effect, we find that the tracking ability of different LETFs can be quite different even though they have similar expense ratios. In addition to the explicit management fees as represented by the expense ratios, other factors can also affect the tracking errors of LETFs. In particular, the asymmetric effect of financing costs on bull vs. bear funds is manifested in our empirical results based on our sample of LETFs tracking the S\&P 500, NASDAQ 100, and the Dow Jones Industrial Average indices. After screening out both the compounding and financing effect, we notice that higher leveraged LETFs tend to underperform the benchmarks more. The lower management efficiency may be attributed to the higher transaction costs involved in delivering the returns for funds with higher leverage ratios. 


\section{References}

Charupat, Narat, and Peter Miu, 2011. The pricing and performance of leveraged exchangetraded funds, Journal of Banking and Finance 35, 966-977.

Charupat, Narat, and Peter Miu, 2013. The pricing efficiency of leveraged exchange-traded funds: Evidence from the U.S. markets, Journal of Financial Research 36, 253-278.

Cheng, Minder, and Ananth Madhavan, 2009. The dynamics of leveraged and inverse exchangetraded funds, Journal of Investment Management 7, 43-62.

Co, Richard, 2009. Leveraged ETFs vs. futures: Where is the missing performance? Chicago Mercantile Exchange research paper, CME Group.

Elton, Edwin J., Martin J. Gruber, George Comer and Kai Li, 2002. Spiders: Where are the bugs? Journal of Business 75 (3), 453-472.

Frino, Alex, and David R. Gallagher, 2001. Tracking S\&P 500 index funds, Journal of Portfolio Management 28 (1), 44-55.

Frino, Alex, and David R. Gallagher, 2002. Is index performance achievable? An analysis of Australian equity index funds, Abacus 38 (2), 200-214.

Frino, Alex, David R. Gallagher, Albert S. Neubert and Teddy N. Oetomo, 2004. Index design and implications for index tracking, Journal of Portfolio Management 30 (2), 89-95. 
Gastineau, Gary L., 2002. Equity index funds have lost their way, Journal of Portfolio Management 28 (2), 55-64.

Gastineau, Gary L., 2004. The benchmark index ETF performance problem, Journal of Portfolio Management 30 (2), 96-103.

Hansen, Lars P., and Robert J. Hodrick, 1980. Forward exchange rates as optimal predictors of future spot rates: An econometric analysis, Journal of Political Economy 88 (5), 829-853.

Harri, Ardian, and B. Wade Brorsen, 2009. The overlapping data problem, Quantitative and Qualitative Analysis in Social Sciences 3 (3), 78-115.

Lu, Lei, Jun Wang and Ge Zhang, 2009. Long term performance of leveraged ETFs. Working paper, SSRN.

ProShares, 2012. Annual report of ProShares Trust (May 31, 2012).

Shum, Pauline M., and Jisok Kang, 2013. Leveraged and inverse ETF performance during the financial crisis, Managerial Finance 39 (5), 467-508. 
Table 1

Descriptive statistics. This table provides summary statistics of the funds in the sample.

The information was obtained from fund issuers' web sites and Bloomberg.

\begin{tabular}{|c|c|c|c|}
\hline Name / Symbol / Multiple & $\begin{array}{c}\text { Inception } \\
\text { date }\end{array}$ & $\begin{array}{c}\text { AUM as of } \\
\text { Dec } 2012 \\
\text { (million) }\end{array}$ & $\begin{array}{c}\text { Net expense } \\
\text { ratio } \\
(2012)\end{array}$ \\
\hline \multicolumn{4}{|l|}{ Panel A: Underlying index = S\&P 500 Index } \\
\hline SPDR S\&P 500 / SPY / +1x & 22 Jan 93 & $\$ 123,001$ & $0.09 \%$ \\
\hline ProShares Short S\&P 500 / SH / -1x & 19 Jun 06 & $\$ 1,850$ & $0.89 \%$ \\
\hline ProShares Ultra S\&P 500 / SSO / +2x & 21 Jun 06 & $\$ 1,279$ & $0.91 \%$ \\
\hline ProShares UltraShort S\&P 500 / SDS / -2x & $11 \mathrm{Jul} 06$ & $\$ 1,561$ & $0.89 \%$ \\
\hline Rydex 2x S\&P 500 / RSU / +2x (see Note 1) & 11 May 07 & $\$ 52$ & $0.70 \%$ \\
\hline Rydex Inverse 2x S\&P 500 / RSW / -2x (see Note 1) & 11 May 07 & $\$ 36$ & $0.70 \%$ \\
\hline ProShares UltraPro S\&P 500 / UPRO / +3x & 23 Jun 09 & $\$ 414$ & $0.95 \%$ \\
\hline ProShares UltraPro Short S\&P 500 / SPXU / -3x & 23 Jun 09 & $\$ 441$ & $0.93 \%$ \\
\hline Direxion Daily S\&P 500 Bull 3x / SPXL / +3x & 11 May 08 & $\$ 219$ & $0.95 \%$ \\
\hline Direxion Daily S\&P 500 Bear 3x / SPXS / -3x & 11 May 08 & $\$ 168$ & $0.95 \%$ \\
\hline \multicolumn{4}{|l|}{ Panel B: Underlying index = NASDAQ 100} \\
\hline PowerShares QQQ / QQQ / +1x (See Note 2) & 10 Mar 99 & $\$ 30,251$ & $0.20 \%$ \\
\hline ProShares Short QQQ / PSQ / -1x & 19 Jun 06 & $\$ 196$ & $0.95 \%$ \\
\hline ProShares Ultra QQQ / QLD / +2x & 19 Jun 06 & $\$ 675$ & $0.95 \%$ \\
\hline ProShares UltraShort QQQ / QID / -2x & $11 \mathrm{Jul} 06$ & $\$ 377$ & $0.95 \%$ \\
\hline ProShares UltraPro QQQ / TQQQ / +3x & 9 Feb 10 & $\$ 318$ & $0.95 \%$ \\
\hline ProShares UltraPro Short QQQ / SQQQ / -3x & 9 Feb 10 & $\$ 134$ & $0.95 \%$ \\
\hline
\end{tabular}


Table 1

Descriptive statistics (continued)

\begin{tabular}{|c|c|c|c|}
\hline Name / Symbol / Multiple & $\begin{array}{c}\text { Inception } \\
\text { date }\end{array}$ & $\begin{array}{c}\text { AUM as of } \\
\text { Dec } 2012 \\
\text { (million) }\end{array}$ & $\begin{array}{c}\text { Net expense } \\
\text { ratio } \\
(2012)\end{array}$ \\
\hline \multicolumn{4}{|l|}{ Panel C: Underlying index = Russell 2000} \\
\hline iShares Russell 2000 / IWM / +1x & 22 May 00 & $\$ 16,409$ & $0.20 \%$ \\
\hline ProShares Short Russell 2000 / RWM / -1x & 23 Jan 07 & $\$ 437$ & $0.95 \%$ \\
\hline ProShares Ultra Russell 2000 / UWM / +2x & 23 Jan 07 & $\$ 127$ & $0.98 \%$ \\
\hline ProShares UltraShort Russell 2000 / TWM / -2x & 23 Jan 07 & $\$ 264$ & $0.95 \%$ \\
\hline Direxion Daily Small Cap Bull / TNA / +3x & 5 Nov 08 & $\$ 732$ & $0.95 \%$ \\
\hline Direxion Daily Small Cap Bear / TZA / -3x & 5 Nov 08 & $\$ 682$ & $0.95 \%$ \\
\hline ProShares UltraPro Russell 2000 / URTY / +3x & 9 Feb 10 & $\$ 68$ & $0.98 \%$ \\
\hline ProShares UltraPro Short Russell 2000 / SRTY / -3x & 9 Feb 10 & $\$ 61$ & $0.95 \%$ \\
\hline \multicolumn{4}{|c|}{ Panel D: Underlying index = Dow Jones Industrial Average } \\
\hline SPDR Dow Jones Industrial Average / DIA / +1x & 14 Jan 98 & $\$ 10,923$ & $0.17 \%$ \\
\hline ProShares Short Dow 30 / DOG / -1x & 19 Jun 06 & $\$ 261$ & $0.95 \%$ \\
\hline ProShares Ultra Dow 30 / DDM / +2x & 19 Jun 06 & $\$ 217$ & $0.95 \%$ \\
\hline ProShares UltraShort Dow 30 / DXD / -2x & 11 Jul 06 & $\$ 272$ & $0.95 \%$ \\
\hline ProShares UltraPro Dow 30 / UDOW / +3x & 9 Feb 10 & $\$ 47$ & $0.95 \%$ \\
\hline ProShares UltraPro Short Dow 30 / SDOW / -3x & 9 Feb 10 & $\$ 82$ & $0.95 \%$ \\
\hline
\end{tabular}

Note: 1) RSU and RSW were liquidated in March 2013.

2) The ticker for PowerShares QQQ NASDAQ 100 ETF was changed from QQQQ to QQQ on March 23, 2011. 
Table 2:

Half-year performance (in percentage form) of funds relative to underlying benchmarks. This table reports the tracking errors $\left(T E_{1}\right.$ and $T E_{2}$ ) of the 10 funds tracking the S\&P 500 Index over various 6-month holding periods. Note that: $r=6$-month holdingperiod return on NAV of fund, $I_{1, t, t+N}=\beta \cdot\left[\prod_{j=1}^{N}\left(1+i_{t+j-1, t+j}\right)-1\right]$, and $I_{2, t, t+N}=\left[\prod_{j=1}^{N}\left(1+\beta \cdot i_{t+j-1, t+j}\right)-1\right]$ where $i_{t}$ is the daily return on benchmark index and $N$ is number of trading days within each 6-month period.

Panel A: Tracking Error $T E_{1}=r-I_{1}$

\begin{tabular}{|c|c|c|c|c|c|c|c|c|c|c|c|c|}
\hline \multirow[b]{2}{*}{$\begin{array}{c}\text { 6-month } \\
\text { period }\end{array}$} & \multirow{2}{*}{$\begin{array}{l}\text { Arith. mean } \\
\text { of daily } \\
\text { index return }\end{array}$} & \multirow{2}{*}{$\begin{array}{l}\text { Std. dev. of } \\
\text { daily index } \\
\text { return }\end{array}$} & \multicolumn{5}{|c|}{ Bull funds } & \multicolumn{5}{|c|}{ Bear funds } \\
\hline & & & $\begin{array}{l}\text { SPY } \\
(+1 x)\end{array}$ & $\begin{array}{l}\text { SSO } \\
(+2 x)\end{array}$ & $\begin{array}{l}\text { RSU } \\
(+2 x)\end{array}$ & $\begin{array}{c}\text { UPRO } \\
(+3 x)\end{array}$ & $\begin{array}{l}\text { SPXL } \\
(+3 x)\end{array}$ & $\begin{array}{c}\text { SH } \\
(-1 \mathrm{x})\end{array}$ & $\begin{array}{l}\text { SDS } \\
(-2 x)\end{array}$ & $\begin{array}{l}\text { RSW } \\
(-2 x)\end{array}$ & $\begin{array}{c}\text { SPXU } \\
(-3 x)\end{array}$ & $\begin{array}{l}\text { SPXS } \\
(-3 x)\end{array}$ \\
\hline $2009 / 07-12$ & 0.165 & 1.064 & -0.09 & 1.94 & 2.15 & 6.82 & 8.99 & 2.65 & 8.53 & 8.79 & 17.21 & 16.28 \\
\hline 2010/01-06 & -0.047 & 1.290 & -0.03 & -1.87 & -1.77 & -4.23 & -3.81 & -2.10 & -5.86 & -5.53 & -11.56 & -13.29 \\
\hline 2010/07-12 & 0.168 & 0.961 & -0.10 & 2.59 & 2.94 & 9.34 & 12.39 & 3.14 & 9.78 & 9.76 & 19.25 & 18.05 \\
\hline 2011/01-06 & 0.050 & 0.810 & -0.01 & -1.30 & -1.11 & -2.87 & -2.24 & -0.77 & -1.43 & -1.39 & -2.27 & -3.50 \\
\hline 2011/07-12 & -0.012 & 1.908 & -0.04 & -4.70 & -4.55 & -12.10 & -15.17 & -4.94 & -13.83 & -13.76 & -26.42 & -25.50 \\
\hline 2012/01-06 & 0.076 & 0.849 & -0.08 & -0.94 & -0.60 & -1.85 & -3.08 & -0.31 & -0.11 & -0.10 & 0.40 & 0.16 \\
\hline 2012/07-12 & 0.049 & 0.759 & -0.08 & -1.14 & -0.94 & -2.31 & -3.04 & -0.69 & -1.34 & -1.24 & -2.16 & -2.27 \\
\hline Median & & & -0.08 & -1.14 & -0.94 & -2.31 & -3.04 & -0.69 & -1.34 & -1.24 & -2.16 & -2.27 \\
\hline
\end{tabular}

Panel B: Tracking Error $T E_{2}=r-I_{2}$

\begin{tabular}{|c|c|c|c|c|c|c|c|c|c|c|c|c|}
\hline \multirow[b]{2}{*}{$\begin{array}{c}\text { 6-month } \\
\text { period }\end{array}$} & \multirow{2}{*}{$\begin{array}{l}\text { Arith. mean } \\
\text { of daily } \\
\text { index return }\end{array}$} & \multirow{2}{*}{$\begin{array}{l}\text { Std. dev. of } \\
\text { daily index } \\
\text { return }\end{array}$} & \multicolumn{5}{|c|}{ Bull funds } & \multicolumn{5}{|c|}{ Bear funds } \\
\hline & & & $\begin{array}{l}\text { SPY } \\
(+1 x)\end{array}$ & $\begin{array}{l}\mathrm{SSO} \\
(+2 \mathrm{x})\end{array}$ & $\begin{array}{l}\mathrm{RSU} \\
(+2 \mathrm{x})\end{array}$ & $\begin{array}{l}\text { UPRO } \\
(+3 x)\end{array}$ & $\begin{array}{l}\text { SPXL } \\
(+3 x)\end{array}$ & $\begin{array}{c}\mathrm{SH} \\
(-1 \mathrm{x})\end{array}$ & $\begin{array}{l}\text { SDS } \\
(-2 x)\end{array}$ & $\begin{array}{l}\text { RSW } \\
(-2 x)\end{array}$ & $\begin{array}{c}\text { SPXU } \\
(-3 x)\end{array}$ & $\begin{array}{c}\text { SPXS } \\
(-3 x)\end{array}$ \\
\hline $2009 / 07-12$ & 0.165 & 1.064 & -0.09 & -0.97 & -0.76 & -1.68 & 0.49 & -0.32 & -0.30 & -0.04 & -0.23 & -1.16 \\
\hline 2010/01-06 & -0.047 & 1.290 & -0.03 & -0.53 & -0.43 & -0.61 & -0.19 & -0.40 & -0.47 & -0.14 & -0.34 & -2.07 \\
\hline 2010/07-12 & 0.168 & 0.961 & -0.10 & -1.02 & -0.67 & -1.58 & 1.47 & -0.28 & -0.21 & -0.23 & -0.17 & -1.37 \\
\hline 2011/01-06 & 0.050 & 0.810 & -0.01 & -0.74 & -0.55 & -1.07 & -0.44 & -0.34 & -0.29 & -0.25 & -0.24 & -1.47 \\
\hline 2011/07-12 & -0.012 & 1.908 & -0.04 & -0.61 & -0.46 & -0.75 & -3.82 & -0.42 & -0.43 & -0.36 & -0.43 & 0.49 \\
\hline 2012/01-06 & 0.076 & 0.849 & -0.08 & -0.77 & -0.43 & -1.14 & -2.37 & -0.32 & -0.28 & -0.27 & -0.24 & -0.48 \\
\hline 2012/07-12 & 0.049 & 0.759 & -0.08 & -0.70 & -0.50 & -0.89 & -1.62 & -0.35 & -0.42 & -0.32 & -0.53 & -0.64 \\
\hline Median & & & -0.08 & -0.74 & -0.50 & -1.07 & -0.44 & -0.34 & -0.30 & -0.25 & -0.24 & -1.16 \\
\hline
\end{tabular}


Table 3:

Regression estimates - conventional regression. This table displays the coefficients from the regressions of the NAV returns of the ten funds that are based on the S\&P 500 index over various holding periods on the returns of the S\&P 500 index (see Equation (5)). The sample period is from June 2009 to December 2012. Overlapping observations are used for holding periods of one month and longer, in which case the standard errors of the estimates are calculated using the Newey-West procedure. The significance for the intercepts is based on whether they are equal to zero. The significance for the slope coefficients is based on whether they are equal to the funds' stated leverage ratios $(\beta)$.

\begin{tabular}{|c|c|c|c|c|c|c|c|c|c|c|c|}
\hline $\begin{array}{c}\text { Fund } \\
\text { (Multiple) }\end{array}$ & Coef. & $\begin{array}{l}\text { Theor. } \\
\text { value }\end{array}$ & Weekly & Monthly & Quarterly & $\begin{array}{c}\text { Fund } \\
\text { (Multiple) }\end{array}$ & Coef. & $\begin{array}{l}\text { Theor. } \\
\text { value }\end{array}$ & Weekly & Monthly & Quarterly \\
\hline \multirow{2}{*}{$\begin{array}{l}\text { SPY } \\
(+1 \mathrm{x})\end{array}$} & $a$ & 0 & $-0.0000^{* *}$ & $-0.0001^{* *}$ & $-0.0002^{* *}$ & \multirow{2}{*}{$\begin{array}{l}\text { SH } \\
(-1 \mathrm{x})\end{array}$} & $a$ & 0 & $-0.0002 * *$ & $-0.0014^{* *}$ & $-0.0064^{* *}$ \\
\hline & $b$ & 1 & $0.997^{* *}$ & $0.998 * *$ & $0.998^{* *}$ & & $b$ & -1 & -0.994 & -0.977 & $-0.925^{* *}$ \\
\hline \multirow{2}{*}{$\begin{array}{l}\text { SSO } \\
(+2 \mathrm{x})\end{array}$} & $a$ & 0 & $-0.0003^{* *}$ & $-0.0017^{* *}$ & $-0.0071^{* *}$ & \multirow{2}{*}{$\begin{array}{l}\text { SDS } \\
(-2 x)\end{array}$} & $a$ & 0 & -0.0004 & $-0.0031^{* *}$ & $-0.0162^{* *}$ \\
\hline & $b$ & 2 & $2.007^{*}$ & 2.015 & $2.051^{* *}$ & & $b$ & -2 & -1.980 & $-1.926^{*}$ & $-1.760 * *$ \\
\hline \multirow{2}{*}{$\begin{array}{l}\text { RSU } \\
(+2 \mathrm{x})\end{array}$} & $a$ & 0 & $-0.0003 * *$ & $-0.0014^{* *}$ & $-0.0062 * *$ & \multirow{2}{*}{$\begin{array}{l}\text { RSW } \\
(-2 \mathrm{x})\end{array}$} & $a$ & 0 & -0.0003 & $-0.0029 * *$ & $-0.0156^{* *}$ \\
\hline & $b$ & 2 & $2.009 *$ & 2.016 & $2.053^{* *}$ & & $b$ & -2 & -1.983 & $-1.928 *$ & $-1.762 * *$ \\
\hline \multirow{2}{*}{$\begin{array}{l}\text { UPRO } \\
(+3 \mathrm{x})\end{array}$} & $a$ & 0 & $-0.0006^{*}$ & $-0.0033^{* *}$ & $-0.0154^{* *}$ & \multirow{2}{*}{$\begin{array}{c}\text { SPXU } \\
(-3 \mathrm{x})\end{array}$} & $a$ & 0 & -0.0006 & $-0.0058 * *$ & $-0.0313^{* *}$ \\
\hline & $b$ & 3 & 3.020 & 3.041 & $3.140^{*}$ & & $b$ & -3 & -2.961 & $-2.842 *$ & $-2.495^{* *}$ \\
\hline \multirow{2}{*}{$\begin{array}{l}\text { SPXL } \\
(+3 x)\end{array}$} & $a$ & 0 & $-0.0007^{*}$ & $-0.0039 * *$ & $-0.0180^{* *}$ & \multirow{2}{*}{$\begin{array}{c}\text { SPXS } \\
(-3 x)\end{array}$} & $a$ & 0 & -0.0007 & $-0.0063^{* *}$ & $-0.0322 * *$ \\
\hline & $b$ & 3 & $3.067 * *$ & 3.098* & $3.230^{* *}$ & & $b$ & -3 & -3.016 & -2.901 & $-2.564 * *$ \\
\hline
\end{tabular}

$* *$ and * indicate statistical significance at the 0.01 and 0.05 levels respectively. 
Table 4:

Regression estimates - proposed regression. This table displays the coefficients from the regressions of the NAV returns on the returns of the underlying indices (see Equation (8)). Overlapping observations are used for holding periods of one month and longer, in which case the standard errors are estimated using the Newey-West procedure. The significance for the coefficients is based on whether they are equal to the corresponding theoretical values.

\begin{tabular}{|c|c|c|c|c|c|c|c|c|c|c|c|}
\hline $\begin{array}{c}\text { Fund } \\
\text { (Multiple) }\end{array}$ & Coef. & $\begin{array}{l}\text { Theor. } \\
\text { value }\end{array}$ & Weekly & Monthly & Quarterly & $\begin{array}{c}\text { Fund } \\
\text { (Multiple) }\end{array}$ & Coef. & $\begin{array}{l}\text { Theor. } \\
\text { value }\end{array}$ & Weekly & Monthly & Quarterly \\
\hline \multirow{4}{*}{$\begin{array}{l}\text { SPY } \\
(+1 x)\end{array}$} & $a$ & 0 & $-0.0000^{* *}$ & $-0.0001^{* *}$ & $-0.0001^{* *}$ & \multirow{4}{*}{$\begin{array}{l}\mathrm{SH} \\
(-1 \mathrm{x})\end{array}$} & $a$ & 0 & $-0.0001^{* *}$ & $-0.0006^{* *}$ & $-0.0017^{* *}$ \\
\hline & $b_{1}$ & 1 & $0.997^{* *}$ & $0.998 * *$ & $1.000^{* *}$ & & $b_{1}$ & -1 & $-1.001^{*}$ & -1.000 & -0.999 \\
\hline & $b_{2}$ & 0 & -0.004 & 0.006 & 0.006 & & $b_{2}$ & 2 & 2.036 & 1.993 & 2.009 \\
\hline & $b_{3}$ & 0 & 1.246 & -0.044 & -0.121 & & $b_{3}$ & 0 & -2.683 & -0.297 & -0.091 \\
\hline \multirow{4}{*}{$\begin{array}{l}\text { SSO } \\
(+2 \mathrm{x})\end{array}$} & $a$ & 0 & $-0.0003^{* *}$ & $-0.0010^{* *}$ & $-0.0032^{* *}$ & \multirow{4}{*}{$\begin{array}{l}\text { SDS } \\
(-2 x)\end{array}$} & $a$ & 0 & $-0.0001^{* *}$ & $-0.0006^{* *}$ & $-0.0019 * *$ \\
\hline & $b_{1}$ & 2 & 2.001 & 1.999 & $1.997^{* *}$ & & $b_{1}$ & -2 & -2.001 & $-1.999 * *$ & $-1.995^{* *}$ \\
\hline & $b_{2}$ & 2 & 1.976 & 1.986 & $1.936^{* *}$ & & $b_{2}$ & 6 & 6.030 & $5.972 * *$ & $5.938 * *$ \\
\hline & $b_{3}$ & 6 & 7.223 & 5.998 & 6.226 & & $b_{3}$ & -6 & -9.199 & -6.596 & -5.760 \\
\hline \multirow{4}{*}{$\begin{array}{l}\text { RSU } \\
(+2 \mathrm{x})\end{array}$} & $a$ & 0 & $-0.0002 * *$ & $-0.0007^{* *}$ & $-0.0023^{* *}$ & \multirow{4}{*}{$\begin{array}{l}\text { RSW } \\
(-2 x)\end{array}$} & $a$ & 0 & $-0.0001 * *$ & $-0.0004 * *$ & $-0.0013 * *$ \\
\hline & $b_{1}$ & 2 & 2.002 & 2.000 & 1.999 & & $b_{1}$ & -2 & $-2.004 * *$ & -2.002 & -1.998 \\
\hline & $b_{2}$ & 2 & 1.906 & $1.957^{* *}$ & $1.938^{* *}$ & & $b_{2}$ & 6 & $6.128^{*}$ & 6.023 & $5.956^{*}$ \\
\hline & $b_{3}$ & 6 & 3.474 & 6.073 & 6.232 & & $b_{3}$ & -6 & 2.697 & -7.405 & -6.247 \\
\hline \multirow{4}{*}{$\begin{array}{l}\text { UPRO } \\
(+3 \mathrm{x})\end{array}$} & $a$ & 0 & $-0.0004^{* *}$ & $-0.0015^{* *}$ & $-0.0048^{* *}$ & \multirow{4}{*}{$\begin{array}{l}\text { SPXU } \\
(-3 x)\end{array}$} & $a$ & 0 & $-0.0001^{* *}$ & $-0.0006^{* *}$ & $-0.0023^{* *}$ \\
\hline & $b_{1}$ & 3 & 3.001 & 2.999 & 3.001 & & $b_{1}$ & -3 & $-3.004 * *$ & -2.997 & $-2.981 * *$ \\
\hline & $b_{2}$ & 6 & $5.934 *$ & $5.880^{*}$ & $5.650 * *$ & & $b_{2}$ & 12 & $12.115^{* *}$ & $11.853^{* *}$ & $11.634^{* *}$ \\
\hline & $b_{3}$ & 24 & $34.328 * *$ & 23.526 & 24.871 & & $b_{3}$ & -24 & -23.807 & -24.772 & $-21.319 * *$ \\
\hline \multirow{4}{*}{$\begin{array}{l}\text { SPXL } \\
(+3 x)\end{array}$} & $a$ & 0 & $-0.0005^{* *}$ & $-0.0018^{*}$ & $-0.0049 *$ & \multirow{4}{*}{$\begin{array}{l}\text { SPXS } \\
(-3 \mathrm{x})\end{array}$} & $a$ & 0 & -0.0002 & -0.0010 & $-0.0043^{*}$ \\
\hline & $b_{1}$ & 3 & $3.054^{* *}$ & $3.048 * *$ & $3.051^{*}$ & & $b_{1}$ & -3 & $-3.068^{* *}$ & $-3.060 * *$ & -3.026 \\
\hline & $b_{2}$ & 6 & $4.827^{* *}$ & 6.295 & $6.701^{*}$ & & $b_{2}$ & 12 & $14.042^{* *}$ & 12.290 & 11.379 \\
\hline & $b_{3}$ & 24 & 90.774 & 20.777 & 24.548 & & $b_{3}$ & -24 & -85.293 & -23.017 & $-16.031^{*}$ \\
\hline
\end{tabular}

** and * indicate statistical significance at the 0.01 and 0.05 levels respectively. 
Table 4:

Regression estimates - proposed regression (continued)

\begin{tabular}{|c|c|c|c|c|c|c|c|c|c|c|c|}
\hline \multicolumn{12}{|c|}{ Panel B: Underlying index = NASDAQ 100 - February 2010 to December 2012} \\
\hline $\begin{array}{c}\text { Fund } \\
\text { (Multiple) }\end{array}$ & Coef. & $\begin{array}{l}\text { Theor. } \\
\text { value }\end{array}$ & Weekly & Monthly & Quarterly & $\begin{array}{c}\text { Fund } \\
\text { (Multiple) }\end{array}$ & Coef. & $\begin{array}{l}\text { Theor. } \\
\text { value }\end{array}$ & Weekly & Monthly & Quarterly \\
\hline \multirow{4}{*}{$\begin{array}{l}\text { QQQ } \\
(+1 x)\end{array}$} & $a$ & 0 & $-0.0000 * *$ & $-0.0002^{* *}$ & $-0.0005^{* *}$ & \multirow{4}{*}{$\begin{array}{l}\text { PSQ } \\
(-1 x)\end{array}$} & $a$ & 0 & $-0.0002^{* *}$ & $-0.0008^{* *}$ & $-0.0022 * *$ \\
\hline & $b_{1}$ & 1 & 1.000 & $0.999 *$ & $0.999 * *$ & & $b_{1}$ & -1 & -1.001 & -1.000 & -0.999 \\
\hline & $b_{2}$ & 0 & -0.007 & 0.007 & 0.003 & & $b_{2}$ & 2 & 2.051 & 2.002 & $2.021^{*}$ \\
\hline & $b_{3}$ & 0 & $5.541^{* *}$ & -0.098 & $-0.091 *$ & & $b_{3}$ & 0 & -1.495 & $-0.381^{*}$ & -0.130 \\
\hline \multirow{4}{*}{$\begin{array}{l}\text { QLD } \\
(+2 x)\end{array}$} & $a$ & 0 & $-0.0003^{* *}$ & $-0.0010^{* *}$ & $-0.0032^{* *}$ & \multirow{4}{*}{$\begin{array}{l}\text { QID } \\
(-2 x)\end{array}$} & $a$ & 0 & $-0.0002^{* *}$ & $-0.0010^{* *}$ & $-0.0030^{* *}$ \\
\hline & $b_{1}$ & 2 & 2.000 & $1.999 * *$ & $1.998^{*}$ & & $b_{1}$ & -2 & -2.001 & $-1.998^{* *}$ & $-1.992 * *$ \\
\hline & $b_{2}$ & 2 & 1.957 & $1.972^{*}$ & $1.925^{* *}$ & & $b_{2}$ & 6 & 6.072 & $5.976^{*}$ & $5.930 * *$ \\
\hline & $b_{3}$ & 6 & 4.131 & 5.857 & $6.374 *$ & & $b_{3}$ & -6 & -3.093 & -6.133 & $-5.210^{* *}$ \\
\hline \multirow{4}{*}{$\begin{array}{l}\text { TQQQ } \\
(+3 x)\end{array}$} & $a$ & 0 & $-0.0003^{* *}$ & $-0.0013^{* *}$ & $-0.0043^{* *}$ & \multirow{4}{*}{$\begin{array}{l}\text { SQQQ } \\
(-3 x)\end{array}$} & $a$ & 0 & $-0.0003^{* *}$ & $-0.0011^{* *}$ & $-0.0038 * *$ \\
\hline & $b_{1}$ & 3 & 3.000 & 3.000 & 3.008 & & $b_{1}$ & -3 & -3.000 & $-2.995^{* *}$ & $-2.976^{* *}$ \\
\hline & $b_{2}$ & 6 & $5.946^{*}$ & $5.882^{*}$ & $5.623^{* *}$ & & $b_{2}$ & 12 & 12.017 & $11.855^{* *}$ & $11.651^{* *}$ \\
\hline & $b_{3}$ & 24 & 22.373 & 23.600 & $26.522^{* *}$ & & $b_{3}$ & -24 & -29.064 & -24.520 & $-20.578 * *$ \\
\hline
\end{tabular}

$* *$ and $*$ indicate statistical significance at the 0.01 and 0.05 levels respectively. 
Table 4:

Regression estimates - proposed regression (continued)

\begin{tabular}{|c|c|c|c|c|c|c|c|c|c|c|c|}
\hline \multicolumn{12}{|c|}{ Panel C: Underlying index = Russell 2000 - February 2010 to December 2012} \\
\hline $\begin{array}{c}\text { Fund } \\
\text { (Multiple) }\end{array}$ & Coef. & $\begin{array}{l}\text { Theor. } \\
\text { value }\end{array}$ & Weekly & Monthly & Quarterly & $\begin{array}{c}\text { Fund } \\
\text { (Multiple) }\end{array}$ & Coef. & $\begin{array}{l}\text { Theor. } \\
\text { value }\end{array}$ & Weekly & Monthly & Quarterly \\
\hline \multirow{4}{*}{$\begin{array}{l}\text { IWM } \\
(+1 \mathrm{x})\end{array}$} & $a$ & 0 & 0.0000 & -0.0000 & 0.0000 & \multirow{4}{*}{$\begin{array}{l}\text { RWM } \\
(-1 x)\end{array}$} & $a$ & 0 & $-0.0003 * *$ & $-0.0013^{* *}$ & $-0.0040 * *$ \\
\hline & $b_{1}$ & 1 & $0.999 * *$ & $0.999 * *$ & 0.999* & & $b_{1}$ & -1 & -1.000 & -0.999 & $-0.994 * *$ \\
\hline & $b_{2}$ & 0 & 0.008 & -0.004 & 0.000 & & $b_{2}$ & 2 & 2.001 & $1.973 * *$ & $1.959 * *$ \\
\hline & $b_{3}$ & 0 & 0.331 & 0.068 & -0.017 & & $b_{3}$ & 0 & $-3.615 * *$ & 0.030 & $0.204^{* *}$ \\
\hline \multirow{4}{*}{$\begin{array}{l}\text { UWM } \\
(+2 x)\end{array}$} & $a$ & 0 & $-0.0001^{* *}$ & $-0.0005^{* *}$ & $-0.0019 * *$ & \multirow{4}{*}{$\begin{array}{l}\text { TWM } \\
(-2 x)\end{array}$} & $a$ & 0 & $-0.0005^{* *}$ & $-0.0022 * *$ & $-0.0070 * *$ \\
\hline & $b_{1}$ & 2 & 2.001 & 2.001 & 2.003 & & $b_{1}$ & -2 & -2.000 & $-1.996 * *$ & $-1.977 * *$ \\
\hline & $b_{2}$ & 2 & 1.978 & $1.953 * *$ & $1.851^{* *}$ & & $b_{2}$ & 6 & $5.951 * *$ & $5.897 * *$ & $5.760 * *$ \\
\hline & $b_{3}$ & 6 & 7.613 & 5.706 & 5.843 & & $b_{3}$ & -6 & -8.665 & -5.773 & $-5.111^{* *}$ \\
\hline \multirow{4}{*}{$\begin{array}{l}\text { TNA } \\
(+3 x)\end{array}$} & $a$ & 0 & $-0.0003^{* *}$ & $-0.0013^{*}$ & $-0.0050 * *$ & \multirow{4}{*}{$\begin{array}{l}\text { TZA } \\
(-3 x)\end{array}$} & $a$ & 0 & $-0.0009 * *$ & $-0.0037 * *$ & $-0.0126^{* *}$ \\
\hline & $b_{1}$ & 3 & 2.998 & 2.998 & 3.011 & & $b_{1}$ & -3 & $-2.997 * *$ & $-2.986 * *$ & $-2.931^{* *}$ \\
\hline & $b_{2}$ & 6 & 5.944 & $5.715^{* *}$ & $5.371 * *$ & & $b_{2}$ & 12 & $11.910^{* *}$ & $11.640^{* *}$ & $11.189 * *$ \\
\hline & $b_{3}$ & 24 & 29.709 & 22.156 & 22.552 & & $b_{3}$ & -24 & -21.805 & -25.537 & $-21.032 * *$ \\
\hline \multirow{4}{*}{$\begin{array}{l}\text { URTY } \\
(+3 x)\end{array}$} & $a$ & 0 & $-0.0001^{*}$ & $-0.0005^{* *}$ & $-0.0027 * *$ & \multirow{4}{*}{$\begin{array}{l}\text { SRTY } \\
(-3 x)\end{array}$} & $a$ & 0 & $-0.0007 * *$ & $-0.0030 * *$ & $-0.0110 * *$ \\
\hline & $b_{1}$ & 3 & 3.000 & 3.002 & $3.021 * *$ & & $b_{1}$ & -3 & -2.999 & $-2.988^{* *}$ & $-2.933^{* *}$ \\
\hline & $b_{2}$ & 6 & $5.930 * *$ & $5.725 * *$ & $5.360 * *$ & & $b_{2}$ & 12 & $11.901^{* *}$ & $11.600^{* *}$ & $11.106^{* *}$ \\
\hline & $b_{3}$ & 24 & 25.923 & 22.445 & 22.811 & & $b_{3}$ & -24 & $-29.073^{*}$ & -24.365 & $-20.281^{* *}$ \\
\hline
\end{tabular}

** and * indicate statistical significance at the 0.01 and 0.05 levels respectively. 
Table 4:

Regression estimates - proposed regression (continued)

\begin{tabular}{|c|c|c|c|c|c|c|c|c|c|c|c|}
\hline \multicolumn{12}{|c|}{ Panel D: Underlying index = Dow Jones Industrial Average - February 2010 to December 2012} \\
\hline $\begin{array}{c}\text { Fund } \\
\text { (Multiple) }\end{array}$ & Coef. & $\begin{array}{l}\text { Theor. } \\
\text { value }\end{array}$ & Weekly & Monthly & Quarterly & $\begin{array}{c}\text { Fund } \\
\text { (Multiple) }\end{array}$ & Coef. & $\begin{array}{l}\text { Theor. } \\
\text { value }\end{array}$ & Weekly & Monthly & Quarterly \\
\hline \multirow{4}{*}{$\begin{array}{c}\text { DIA } \\
(+1 \mathrm{x})\end{array}$} & $a$ & 0 & $-0.0000 * *$ & $-0.0001^{* *}$ & $-0.0004^{* *}$ & \multirow{4}{*}{$\begin{array}{l}\text { DOG } \\
(-1 x)\end{array}$} & $a$ & 0 & $-0.0002^{* *}$ & $-0.0006^{* *}$ & $-0.0019 * *$ \\
\hline & $b_{1}$ & 1 & $0.998 * *$ & $0.998 * *$ & $0.998 * *$ & & $b_{1}$ & -1 & -1.000 & -1.000 & -0.999 \\
\hline & $b_{2}$ & 0 & -0.007 & -0.005 & -0.009 & & $b_{2}$ & 2 & $2.060 *$ & 2.001 & 2.018 \\
\hline & $b_{3}$ & 0 & 1.662 & 0.433 & 0.086 & & $b_{3}$ & 0 & 3.111 & -0.097 & -0.009 \\
\hline \multirow{4}{*}{$\begin{array}{l}\text { DDM } \\
(+2 x)\end{array}$} & $a$ & 0 & $-0.0003^{* *}$ & $-0.0011^{* *}$ & $-0.0034^{* *}$ & \multirow{4}{*}{$\begin{array}{l}\text { DXD } \\
(-2 x)\end{array}$} & $a$ & 0 & $-0.0002 * *$ & $-0.0007 * *$ & $-0.0023 * *$ \\
\hline & $b_{1}$ & 2 & 1.999 & $1.999 * *$ & $1.995^{* *}$ & & $b_{1}$ & -2 & -2.000 & -2.000 & $-1.994 * *$ \\
\hline & $b_{2}$ & 2 & $1.921 *$ & 1.981 & $1.934^{* *}$ & & $b_{2}$ & 6 & $6.120^{* *}$ & 5.996 & $5.953 *$ \\
\hline & $b_{3}$ & 6 & 6.678 & 6.313 & 6.314 & & $b_{3}$ & -6 & -1.986 & -6.769 & -5.455 \\
\hline \multirow{4}{*}{$\begin{array}{l}\text { UDOW } \\
(+3 \mathrm{x})\end{array}$} & $a$ & 0 & $-0.0004 * *$ & $-0.0015^{* *}$ & $-0.0047 * *$ & \multirow{4}{*}{$\begin{array}{l}\text { SDOW } \\
(-3 x)\end{array}$} & $a$ & 0 & $-0.0002 * *$ & $-0.0007 * *$ & $-0.0025^{* *}$ \\
\hline & $b_{1}$ & 3 & 3.000 & $2.997^{* *}$ & 2.996 & & $b_{1}$ & -3 & -3.000 & -2.998 & $-2.983 * *$ \\
\hline & $b_{2}$ & 6 & $5.887 * *$ & $5.892 * *$ & $5.706^{* *}$ & & $b_{2}$ & 12 & $12.098^{*}$ & $11.883^{* *}$ & $11.700^{* *}$ \\
\hline & $b_{3}$ & 24 & 28.342 & 23.533 & 25.087 & & $b_{3}$ & -24 & -24.636 & -25.339 & $-21.276 * *$ \\
\hline
\end{tabular}

** and * indicate statistical significance at the 0.01 and 0.05 levels respectively. 
Table 5:

Panel regression of NAV returns of all funds. This table displays the coefficients from the panel regression of Equation (9) based on quarterly holding period returns. Weekly overlapping observations are used. The intercepts $\left(a_{s}\right)$ are presented in basis points. The significance for the intercepts and the slope coefficient $\gamma_{r}$ is based on whether they are equal to zero. The significance for the slope coefficients $\gamma_{1}, \gamma_{2}$, and $\gamma_{3}$ is based on whether they are equal to unity.

\begin{tabular}{|c|c|c|c|c|}
\hline & Fund & Regression (i) & Regression (ii) & Regression (iii) \\
\hline$a_{1}$ & SPY (+1x) & $13.681^{* *}$ & $-1.664 * *$ & $-1.683 * *$ \\
\hline$a_{2}$ & SH (-1x) & $-62.171^{* *}$ & $-18.250^{* *}$ & $-24.479 * *$ \\
\hline$a_{3}$ & $\mathrm{SSO}(+2 \mathrm{x})$ & $-27.999 *$ & $-31.449 * *$ & $-28.352 * *$ \\
\hline$a_{4}$ & RSU (+2x) & -18.299 & $-21.749 * *$ & $-18.652^{* *}$ \\
\hline$a_{5}$ & SDS (-2x) & $-137.574 * *$ & $-19.821^{* *}$ & $-29.150 * *$ \\
\hline$a_{6}$ & RSW (-2x) & $-134.979 * *$ & $-17.226^{* *}$ & $-26.555^{* *}$ \\
\hline$a_{7}$ & UPRO (+3x) & $-77.230 * *$ & $-42.881^{* *}$ & $-36.658 * *$ \\
\hline$a_{8}$ & SPXL (+3x) & $-92.203^{* *}$ & $-57.854^{* *}$ & $-51.632 * *$ \\
\hline$a_{9}$ & SPXU (-3x) & $-243.116^{* *}$ & $-20.284^{* *}$ & $-32.713^{* *}$ \\
\hline$a_{10}$ & SPXS (-3x) & $-264.517 * *$ & $-41.684 * *$ & $-54.113^{* *}$ \\
\hline$a_{11}$ & QQQ (+1x) & $16.261^{* *}$ & $-4.187 * *$ & $-4.212^{* *}$ \\
\hline$a_{12}$ & PSQ (-1x) & $-69.974 * *$ & $-24.266^{* *}$ & $-30.490 * *$ \\
\hline$a_{13}$ & QLD (+2x) & -13.277 & $-30.762^{* *}$ & $-27.677^{* *}$ \\
\hline$a_{14}$ & QID (-2x) & $-149.169 * *$ & $-30.642 * *$ & $-39.962 * *$ \\
\hline$a_{15}$ & TQQQ (+3x) & -41.461 & $-34.422 * *$ & $-28.216^{* *}$ \\
\hline$a_{16}$ & SQQQ (-3x) & $-253.252 * *$ & $-32.946 * *$ & $-45.364 * *$ \\
\hline$a_{17}$ & IWM (+1x) & $15.443^{* *}$ & 0.443 & 0.425 \\
\hline$a_{18}$ & RWM (-1x) & $-122.811^{* *}$ & $-40.629 * *$ & $-46.851^{* *}$ \\
\hline$a_{19}$ & UWM (+2x) & $-48.499 * *$ & $-13.970 * *$ & $-10.863^{* *}$ \\
\hline$a_{20}$ & TWM (-2x) & $-298.743 * *$ & $-64.543 * *$ & $-73.855^{* *}$ \\
\hline$a_{21}$ & TNA (+3x) & $-176.457 * *$ & $-30.525^{* *}$ & $-24.272^{* *}$ \\
\hline$a_{22}$ & URTY (+3x) & $-150.616^{* *}$ & -4.684 & 1.570 \\
\hline$a_{23}$ & TZA (-3x) & $-556.175^{* *}$ & $-97.468 * *$ & $-109.866^{* *}$ \\
\hline$a_{24}$ & SRTY (-3x) & $-537.053^{* *}$ & $-78.346 * *$ & $-90.744 * *$ \\
\hline$a_{25}$ & DIA (+1x) & $12.416^{* *}$ & $-3.279 * *$ & $-3.298 * *$ \\
\hline$a_{26}$ & DOG $(-1 x)$ & $-60.484^{* *}$ & $-20.325^{* *}$ & $-26.555^{* *}$ \\
\hline$a_{27}$ & DDM (+2x) & $-27.621^{* *}$ & $-34.216^{* *}$ & $-31.123^{* *}$ \\
\hline$a_{28}$ & DXD (-2x) & $-129.778 * *$ & $-25.329 * *$ & $-34.656^{* *}$ \\
\hline$a_{29}$ & UDOW (+3x) & $-72.942 * *$ & $-45.312^{* *}$ & $-39.105^{* *}$ \\
\hline$a_{30}$ & SDOW (-3x) & $-216.788 * *$ & $-24.247 * *$ & $-36.667^{* *}$ \\
\hline$\gamma_{1}$ & & $0.935^{* *}$ & $0.997 * *$ & $0.997 * *$ \\
\hline$\gamma_{2}$ & & & $0.964 * *$ & $0.964 * *$ \\
\hline$\gamma_{3}$ & & & $0.934^{* *}$ & $0.932 * *$ \\
\hline$\gamma_{r}$ & & & & $-0.0818^{* *}$ \\
\hline
\end{tabular}

** and * indicate statistical significance at the 0.01 and 0.05 levels respectively. 